\title{
Effect of Spironolactone on Chronic Allograft Nephropathy in Rats
}

\section{Steven M. Cogar ${ }^{1,5}$, Chad W. Schmiedt" ${ }^{1 *}$, Cathy A. Brown ${ }^{4}$, Michel L. Vandenplas ${ }^{3}$, Christy Chessman ${ }^{1}$ and David J. Hurley ${ }^{2}$}

${ }^{1}$ Department of Small Animal Medicine and Surgery, University of Georgia College of Veterinary Medicine, Athens, GA, USA

${ }^{2}$ Population Health, University of Georgia College of Veterinary Medicine, Athens, GA, USA

${ }^{3}$ Large Animal Medicine, University of Georgia College of Veterinary Medicine, Athens, GA, USA

${ }^{4}$ Athens Veterinary Diagnostic Laboratory, University of Georgia College of Veterinary Medicine, Athens, GA, USA

${ }^{5}$ Carolina Veterinary Specialists, Winston-Salem, NC, USA

\begin{abstract}
Objective: Chronic allograft nephropathy (CAN) is common following renal transplantation in cats and people. Aldosterone potentiates ongoing renal injury; however its role in CAN is less defined. Spironolactone, an aldosterone receptor blocker, is protective in other rodent models of renal injury. The purpose of this study was to evaluate spironolactone on the development of CAN in a rat model
\end{abstract}

Animals: Fisher and Lewis, adult, male rats.

Procedures: A Lewis to Fisher model of CAN was used. Rats were divided into 4 groups, 2 nephrectomy controls (CON) and 2 transplantation (TX) groups. Two groups (a CON and TX) received tap water $(0.25 \mathrm{ml} /$ day orally), and the remaining 2 received spironolactone $(10 \mathrm{mg} / \mathrm{kg}$ orally) daily for 16 weeks post transplantation. Serum creatinine concentration, urine-protein: urine-creatinine (UP: UC), and changes in renal cortex gene expression were measured during and at 16 weeks after transplantation.

Results: There were no significant differences in any of the outcome measures when the 2 TX groups were compared. TX rats had significantly more $(p=0.0002)$ histological lesions consistent with CAN and elevation in TNF- $\alpha$ $(p=0.0402)$ compared to CON animals.

Conclusions and clinical relevance: In this study, spironolactone did not protect against the development or progression of CAN.

Impact for human medicine: The impact of aldosterone on the occurrence of CAN in humans following renal transplantation remains an area of investigation.

\begin{abstract}
Abbreviations: CAN: Chronic allograft nephropathy; RAAS: Renin angiotensin aldosterone system; TGF- $\beta$ : Transforming growth factor beta; TNF- $\alpha$ : Tumor necrosis factor - alpha; INF- $\gamma$ : Interferon gamma; Colla1: Collagen 1 alpha 1; End1: endothelin 1; CTGF: Connective tissue growth factor; PDGF: Platelet derived growth factor; MMP2: Matrix metalloproteinase 2; MMP 9: Matrix metalloproteinase 9; PCR: Polymerase chain reaction; RT-qPCR: Real time - quantitative polymerase chain reaction; UP:UC: Urine protein: creatinine ratio; ACE: Angiotensin converting enzyme
\end{abstract}

\section{Introduction}

The efficacy of renal transplantation is severely impacted by the occurrence of chronic allograft nephropathy (CAN), a common condition resulting in progressive allograft failure in human and veterinary patients. Histologic lesions associated with CAN were identified in 45 of 65 cats in a study of histologic lesions associated with feline renal allographs [1]. A common comorbidity in people and cats before and during allograft degradation is systemic hypertension. As CAN progresses, the pathophysiologic mechanisms for hypertension are amplified, creating a vicious cycle ultimately resulting in a more rapid decline in allograft function. Only $3.5 \%$ of human renal transplant recipients have normal blood pressure without medication 1 year after renal transplantation [2].

A common treatment strategy for management of hypertension secondary to kidney disease is pharmacologic modification of the renin-angiotensin-aldosterone system (RAAS). One goal of RAAS modification is reduction of the concentration of aldosterone, a mineralocorticoid secreted from the adrenal glands after stimulation from angiotensin II. Aldosterone's main physiologic action is to increase renal tubular reabsorption of sodium and water, which results in plasma volume expansion. Acutely, common RAAS modification strategies will result in systemic suppression of aldosterone, however this suppression is often not durable; this unsustained suppression is termed 'aldosterone escape,' and occurs nearly $40 \%$ of the time in humans receiving angiotensin converting enzyme inhibitor therapy [3]. It is this unsuppressed aldosterone that may be a particular concern in renal transplantation recipients because aldosterone promotes renal inflammation, endothelial dysfunction, and fibrosis, actions thought to be mediated through plasminogen activator inhibitor- 1 and TGF- $\beta$, among other pro-inflammatory or pro-fibrotic cytokines [4-9]. With the introduction of selective aldosterone receptor blockers, inhibition of aldosterone is becoming an increasingly common strategy to battle hypertension, as well as mitigating chronic aldosterone-mediated renal injury [10].

Inhibition of aldosterone reduced renal injury in various rodent models including remnant kidney models [11], stroke prone spontaneously hypertensive rats $[8,12,13], \mathrm{N}(\mathrm{G})$-nitro-L-arginine

*Corresponding author: Chad Schmiedt, Department of Small Animal Medicine and Surgery, University of Georgia College of Veterinary Medicine, Athens, GA E-mail: cws@uga.edu

Received December 14, 2011; Accepted January 03, 2012; Published January 05, 2012

Citation: Cogar SM, Schmiedt CW, Brown CA, Vandenplas ML, Chessman C, et al. (2012) Effect of Spironolactone on Chronic Allograft Nephropathy in Rats. J Nephrol Therapeutic S4:002. doi:10.4172/2161-0959.S4-004

Copyright: ( 2012 Cogar SM, et al. This is an open-access article distributed under the terms of the Creative Commons Attribution License, which permits unrestricted use, distribution, and reproduction in any medium, provided the original author and source are credited. 
methyl ester treated hypertensive rats [14], radiation induced renal injury [15], adriamycin induced renal injury [16], and cyclosporine nephrotoxicity. One study in rats treated with spironolactone documented amelioration of transplant vasculopathy with relatively high $(20 \mathrm{mg} / \mathrm{kg})$ doses of spironolactone; rats were evaluated at one time point, 12 weeks after transplantation [17]. In that study, the reduction in vasculopathy was evidenced by a reduction in the number of large $(>100 \mu \mathrm{m})$ arteries affected with neointimal hyperplasia. However, in all groups the severity of lesions in affected vessels was not changed, leading the authors to postulate spironolactone specifically reduced initiation, not progression, of neointimal hyperplasia [17]. Additionally, spironolactone caused improved creatinine clearance, reduced arteriopathy, and reduced interstitial fibrosis in a Wistar rat model of cyclosporine nephrotoxicity [18]. In that experiment, TGF- $\beta$, collagen I, and fibronectin up-regulation were also decreased in rats treated with spironolactone [18-20]. Clinically, aldosterone receptor blockers resulted in a reduction in proteinuria in human patients with naturally occurring renal disease [3,19-22].

There is ample evidence that inhibition of aldosterone reduces proinflammatory and pro-fibrotic processes in other models of renal injury, but definitive evidence of a functional benefit in renal transplantation and CAN models is lacking. Therefore, the objective of this study is to evaluate the effect of spironolactone on renal allograft function, markers of allograft injury, and up-regulation of pro-inflammatory and pro-fibrotic gene expression in the Fisher to Lewis model of CAN. Our hypothesis is that at spironolactone will reduce allograft damage evidenced by decreased proteinuria, improved allograft function, reduced histologic evidence of CAN lesions, and a reduction in proinflammatory and pro-fibrotic gene expression. The ultimate goal is to reduce the occurrence of CAN and increase the long-term functionality of renal allographs in people and cats.

\section{Materials and Methods}

\section{Animals}

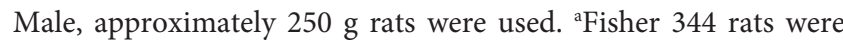
kidney donors, and Lewis rats were heterotropic renal transplant recipients. To control for reduction of glomeruli, control Lewis rats underwent a unilateral nephrectomy. All rats were housed individually with a 12-hour light-dark cycle, received ad labium water and standard rat chow. All procedures were approved by the Institutional Animal Care and Use Committee.

\section{Experimental design}

Lewis rats were assigned to 1 of 4 control or experimental groups and renal donors were assigned to recipients using a random number generator. The control groups underwent right nephrectomy and received either $0.25 \mathrm{~mL}$ of water (water control group, $\mathrm{n}=4$ ) or 2.5 $\mathrm{mg}$ of spironolactone (spironolactone control group, $\mathrm{n}=4,10 \mathrm{mg} / \mathrm{mL}$ concentration) per day. The experimental groups which underwent heterotopic renal transplantation and received either $2.5 \mathrm{mg}$ of spironolactone (spironolactone transplant group, $\mathrm{n}=8,10 \mathrm{mg} / \mathrm{mL}$ concentration) or $0.25 \mathrm{~mL}$ of water (water transplant group, $\mathrm{n}=8$ ). In all rats medication was given daily by oral gavage initiated 2 days prior to surgery. Additionally, all rats received cyclosporine $(1.5 \mathrm{mg} / \mathrm{kg} /$ day $)$ for 12 days also initiated 2 days prior to surgery.

\section{Kidney transplantation and nephrectomy}

All transplants were performed using an aortic and inferior vena cava donor conduit as described [23]. Ureteral implantation was performed using a donor bladder cuff. All animals were pre-medicated with $0.02 \mathrm{mg} / \mathrm{kg}$ buprenorphine. Anesthesia induced and maintained with $1.5-2 \%$ isoflurane in $100 \%$ oxygen, and $3 \mathrm{~mL}$ of sterile saline was administered subcutaneously prior to surgery. The kidney was flushed and briefly stored in cold $\left(\sim 4^{\circ} \mathrm{C}\right)$ University of Wisconsin-solution. ${ }^{\mathrm{b}}$ The warm and cold ischemic times were recorded for each transplant. Ten days after transplantation all recipient animals underwent a double nephrectomy of the native kidneys.

All nephrectomies were performed with a single ligation including the renal artery, vein, and ureter. At the conclusion of the study (16 weeks post transplantation), a necropsy was performed on all animals. At this time the allograft and any grossly abnormal tissues were collected for histopathology and the renal cortex of the native (control) and allograft (transplant recipients) was collected and immediately placed in an RNA preservation solution ${ }^{c}$ for 24 hours and stored in a $-80^{\circ} \mathrm{C}$ freezer until RT-qPCR analysis.

\section{Functional analysis}

Serum creatinine was measured before surgery, on the day of the native nephrectomy (day 0), and weeks $0.14,0.47,1,2,3,4,6,8,10,12$, and 16. Urine protein: urine creatinine (UP: UC) was measured before surgery and monthly thereafter for 4 months.

\section{Real-Time RT-qPCR assays}

Frozen cortical tissue (approximately $30 \mathrm{mg}$ ) was allowed to thaw at room temperature $\left(\sim 22^{\circ} \mathrm{C}\right)$, minced with a sterile blade, transferred into a motorized micro-donuce, and homogenized with $600 \mu \mathrm{l}$ RA extraction buffer. ${ }^{d}$ RNA was isolated using the same kit with the inclusion of an on filter DNase I digestion step to remove any potential of genomic DNA contamination. Sample quantity of the RNA was determined by Nanodrop spectrophotometer and sample quality was assessed from 260:280 $\mathrm{nm}$ ratios. Only RNA having ratios between 1.8 and 2.2 were used for determination of gene expression profiles by quantitative TaqMan RT-qPCR assays. Expressions of 9 genes (TGF- $\beta$, TNF- $\alpha$, INF- $\gamma$, Col1 $\alpha 1$, End1, CTGF, PDGF, MMP2, and MMP 9) that have been reported to play a role in allograft damage were compared to $18 \mathrm{~S}$ ribosomal gene expression. Pre-validated TaqMan probes and primer kits were used ${ }^{\mathrm{e}}$ with RT-qPCR reagents from the same company. Quantitative PCR analysis based on the TaqMan methodology was performed using a real time-PCR system. ${ }^{f}$ Samples were tested in triplicate and then averaged. For control groups the baseline sample was the nephrectomized kidney; for experimental transplant groups the baseline sample was the nontransplanted kidney from the donor rat to avoid confusion from potential strain-specific genetic variation [24]. Results were expressed using the $\Delta \Delta \mathrm{C}_{\mathrm{T}}$ method such that $\Delta \Delta \mathrm{C}_{\mathrm{T}}=\left(\mathrm{C}_{\mathrm{T}}\right.$ gene of interest $\left.\left.-\mathrm{C}_{\mathrm{T}} 18 \mathrm{~S}\right)_{\text {baceline }}-\left(\mathrm{C}_{\mathrm{T}} \text { gene of interest }-\mathrm{C}_{\mathrm{T}} 18 \mathrm{~S}\right)_{\text {ateuthanasi }}\right)$. Fold change in gene expression was calculated with the formula $2^{-\Delta \Delta \mathrm{CT}}$ with $>2$-fold changes in expression considered biologically relevant.

\section{Histological evaluation}

Renal tissue harvested at time zero and upon euthanasia were embedded in paraffin and sectioned in $4 \mu \mathrm{m}$ sections. Samples from each kidney were stained with periodic acid-Schiff with hematoxylin and hematoxylin and eosin. All samples were evaluated by a blinded, board-certified pathologist. Two Periodic acid-Schiff - Hematoxylinstained sagittal sections of tissue from each donor, recipient, and transplant kidney were evaluated histologically for evidence of 
transplant vasculopathy. Eight to 16 arteries were identified in each transplant kidney (approximately half being 50-90 um in diameter and half being 100-220 um in diameter). Samples were further scored using the Banff 07 renal allograft histological evaluation system [25].

\section{Statistical analysis}

All analysis was performed using statistical software.g.h A repeated measures ANOVA that recognized multiple observations as belonging to the same rat was used to test for differences between groups and time points in UP:UC and serum creatinine concentration measurements. The full model included fixed factors of week and group and a week by group interaction term and a random factor of rat. Multiple comparisons were adjusted for using Tukey's test. Intergroup data were first evaluated for normality with a Kolmogorov-Smirnov test. Groups were then compared with a Student's t-test or Mann Whitney U, as appropriate; or 1-way ANOVA followed by a Tukey's test or a KruskalWallis ANOVA on ranks followed by a Dunn's test, as appropriate. Data is expressed as mean \pm SEM and significance was set at $p \leq 0.05$.

\section{Results}

\section{Ischemia times}

The warm ischemia time for the spironolactone transplant was $31.38 \pm 1.82$ minutes and for the water transplant group was $28.84 \pm$ 0.56 minutes $(\mathrm{p}=0.34)$. Cold ischemia time for the spironolactone transplant group was $46.91 \pm 4.09$ minutes and for the water transplant group was $52.88 \pm 2.4$ minutes $(\mathrm{p}=0.33)$. No significant difference was found in warm or cold ischemia times between groups.

\section{Survival and functional analysis}

Four rats did not complete the study. Three ( 2 in the spironolactone transplant group and 1 in water transplant group) developed pyelonephritis or had evidence of multifocal septic cortical abscessation on histopathology. Another rat in the spironolactone transplant group developed hydronephrosis secondary to ureteral calculi. These rats were excluded from all analyses.

There were significant overall differences between weeks ( $p=0.0169$ ), but not groups, in UP: UC. Generally, there was an increase in UP: UC values after transplantation in both groups throughout the study (Figure 1). When week 16 UP: UC levels were compared to week 0 there was a significant increase in both transplant groups compared to the nephrectomy groups.

For serum creatinine concentration, there were significant overall differences between weeks $(\mathrm{p}<0.0001)$ and groups $(\mathrm{p}<0.0001$, Table 1$)$. However experimental groups did not differ at any time point.

\section{Real time RT-qPCR}

Tissue obtained from the renal cortices was evaluated for relative expression of 9 genes implicated in the progression of CAN using prevalidated, commercially-available RT-qPCR assays. There was a significant increase in TNF- $\alpha$ gene expression within the renal cortical tissue in the transplant spironolactone group compared to the water nephrectomy control group $(\mathrm{p}=0.0039)$ (Figure 2). However, no significant difference was noted between transplant groups for overall expression of TNF- $\alpha$.

Endothelin mRNA expression was significantly increased in control rats that received spironolactone, compared to those that received water (fold change water control $=1.01 \pm 0.16$, spironolactone control $=3.12 \pm 0.72, \mathrm{P}=0.03)$.

Biologically significant differences (fold change $>2$ ) were not found in expression of PDGF, TGF- $\beta$, INF- $\gamma$, Col1 $\alpha 1$, CTGF, MMP2, or MMP 9 genes when individual groups, types of medication, or surgical procedure were compared.

\section{Histopathology}

There were no specimens noted to have acute arteritis, acute glomerulitis, chronic intimal fibrosis, neointimal formation, or chronic arterial hyalinosis. Likewise, no control specimens scored positive for any of the parameters evaluated, except for one rat in the water

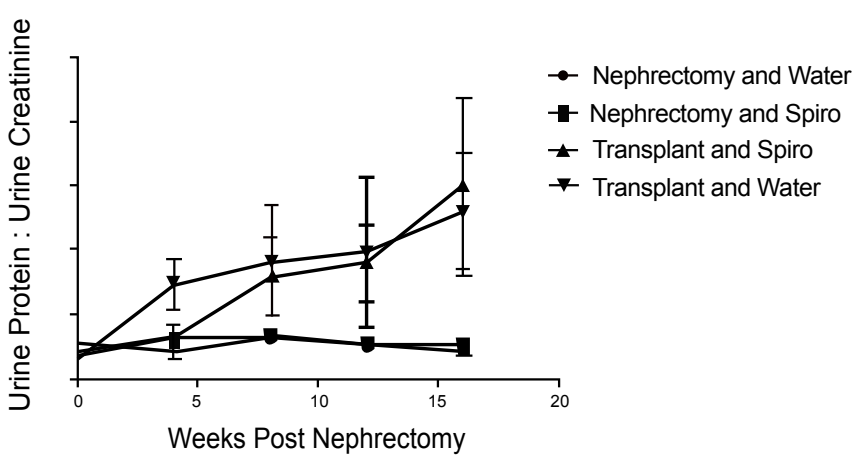

Figure 1: Urine protein: creatinine values for Fisher to Lewis rats undergoing heterotopic renal transplantation, bilateral native nephrectomy, and receiving water (triangle, $0.25 \mathrm{~mL}$ oral, once daily) or spironolactone (diamond, $10 \mathrm{mg} / \mathrm{kg}$, oral, once daily). Control rats underwent uninephrectomy and received water (cricles) or spironolactone (squares) at the same doses and frequencies. ${ }^{*}=$ significant increase in UP:UC in both transplant groups ( $p=0.03$ spironolactone and 0.04 water) compared to week 0 . No difference was detected between groups at any time point.

\begin{tabular}{|c|c|c|c|c|}
\hline $\begin{array}{c}\text { Week post } \\
\text { nephrectomy }\end{array}$ & $\begin{array}{c}\text { Water and } \\
\text { nephrectomy } \\
\text { control }\end{array}$ & $\begin{array}{l}\text { Spironolactone } \\
\text { and } \\
\text { nephrectomy } \\
\text { control }\end{array}$ & $\begin{array}{c}\text { Spironolactone } \\
\text { and } \\
\text { transplantation }\end{array}$ & $\begin{array}{l}\text { Water and } \\
\text { transplantation }\end{array}$ \\
\hline 0 & $0.50 \pm 0.00$ & $0.50 \pm 0.00$ & $0.52 \pm 0.02$ & $0.53 \pm 0.02$ \\
\hline 0.14 & $0.80 \pm 0.00^{a, b_{,}^{*}}$ & $0.80 \pm 0.03^{c, d}$ & $1.36 \pm 0.18^{\mathrm{a}, \mathrm{c}, \mathrm{c}^{\star}}$ & $1.24 \pm 0.08^{\mathrm{b}, \mathrm{d}, *}$ \\
\hline 0.42 & $0.80 \pm 0.07^{*}$ & $0.70 \pm 0.04^{e}$ & $1.06 \pm 0.12^{e_{, *}^{*}, \#}$ & $0.96 \pm 0.04^{*}, \#$ \\
\hline 1 & $0.60 \pm 0.04^{f}$ & $0.60 \pm 0.00^{9}$ & $0.88 \pm 0.08^{\mathrm{f}, \mathrm{g}^{*}, \#}$ & $0.79 \pm 0.05^{*}, \#$ \\
\hline 2 & $0.60 \pm 0.00$ & $0.58 \pm 0.03$ & $0.80 \pm 0.08^{*}, \#, \$, \%$ & $0.84 \pm 0.06^{*}, \#$ \\
\hline 3 & $0.58 \pm 0.03$ & $0.58 \pm 0.03$ & $0.80 \pm 0.63^{*}, \#, \$, \%$ & $0.71 \pm 0.04^{\#, \$}$ \\
\hline 4 & $0.63 \pm 0.03$ & $0.63 \pm 0.03^{h}$ & $0.86 \pm 0.08^{h_{,}^{*}, \#}$ & $0.79 \pm 0.01^{*}, \#$ \\
\hline 6 & $0.65 \pm 0.03$ & $0.60 \pm 0.00$ & $0.80 \pm 0.08^{*}, \#, \$, \%$ & $0.76 \pm 0.02^{* \#}$ \\
\hline 8 & $0.63 \pm 0.03$ & $0.68 \pm 0.03$ & $0.82 \pm 0.04^{*}, \#$ & $0.81 \pm 0.03^{*}, \#$ \\
\hline 10 & $0.63 \pm 0.03$ & $0.68 \pm 0.03$ & $0.76 \pm 0.07^{\#, \$, \%}$ & $0.70 \pm 0.02^{\#, \$}$ \\
\hline 12 & $0.63 \pm 0.03$ & $0.65 \pm 0.03$ & $0.92 \pm 0.09^{*}, \#$ & $0.77 \pm 0.03^{*}$ \\
\hline 14 & $0.58 \pm 0.03$ & $0.60 \pm 0.00$ & $0.76 \pm 0.09^{\#, \$}$ & $0.69 \pm 0.01^{\#, \$}$ \\
\hline 16 & $0.68 \pm 0.03$ & $0.65 \pm 0.03$ & $0.90 \pm 0.13^{*}, \#$ & $0.81 \pm 0.03^{*, \#}$ \\
\hline
\end{tabular}

Table 1: Mean \pm SEM serum creatinine concentrations $(\mathrm{mg} / \mathrm{dL})$ of rats on weeks following nephrectomy only (controls) or heterotopic renal transplantation and bilateral nephrectomy. Rats either received water $(0.25 \mathrm{~mL}$, oral, daily) or spironolactone $(10 \mathrm{mg} / \mathrm{kg}$, oral, daily). Values sharing a letter are statistically different (comparisons between groups). ${ }^{*}=$ statistically different from baseline within a group, $\#=$ statistically different than week 0.14 with a group, $\$=$ statistically different than week 0.42 within a group, $\%=$ statistically different than week 1 within a group. 


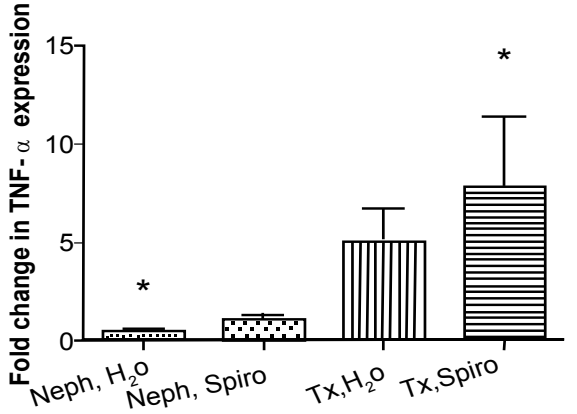

Figure 2: Fold change in gene expression of renal cortical TNF - $\alpha$ in Lewis rats 16 weeks after nephrectomy (neph) or heterotopic renal transplantation from Fisher rats $(\mathrm{Tx})$. Rats received either spironolactone $(2.5 \mathrm{mg}$, spiro) or an equivalent volume of water $\left(0.25 \mathrm{ml}, \mathrm{H}_{2} \mathrm{O}\right)$ by gavage daily. All rats received 1.5 $\mathrm{mg} / \mathrm{kg} /$ day of oral cyclosporine for 2 days prior to transplantation and 10 days post transplantation. Rats undergoing heterotopic renal transplantation and receiving spironolactone had significantly elevated expression of TNF $-\alpha$ in the renal cortex compared to nephrectomized rats receiving water $\left({ }^{*}, p=0.0136\right)$. When rats were divided and compared based on transplantation status alone, rats that received transplants had a significantly greater TNF $-\alpha$ expression compared to nephrectomy controls $(p=0.0023)$.

control group that had evidence of mild mesangial matrix expansion. When control animals were compared to transplant recipients, there was a significant increase in acute interstitial inflammation $(p=0.0009)$, mesangial matrix expansion ( $\mathrm{p}=0.0173$ ), and chronic tubular atrophy $(\mathrm{p}=0.0225)$ in transplant animals. No significant difference was found in any of the parameters examined between transplantation groups.

\section{Discussion}

As expected, the Fisher to Lewis allograft model produced progressive allograft dysfunction as evidenced by increasing UP: UC, up regulation of TNF - a gene expression, and characteristic histopathological lesions. However, this study failed to demonstrate that spironolactone improved renal allograft function, altered proinflammatory gene expression, or changed microscopic lesions characteristic of CAN compared to rats that just received water.

Our study mirrors a previous study in the Dark Agouti-to-WistarFurth renal allograft transplant model which found spironolactone administration following allograft transplantation did not have any significant effect on body weight, proteinuria, creatinine clearance, serum urea, or the development of focal glomerular sclerosis or interstitial fibrosis 12 weeks after transplantation [17]. However, the findings of our study differ slightly from that study, which reports a reduction of frequency, but not severity, of transplant vascuolpathy in allograft recipients which received spironolactone [17].

The most likely reason for the conflicting result is the use of cold saline as an allograft storage solution compared the University of Wisconsin storage solution used for allograft storage in the study reported here. It is well understood that cold ischemic injury will be greater in organs stored in saline compared to University of Wisconsin organ storage solution and that cold ischemic injury to vessels will result in greater neointimal hyperplasia [26,27]. Aldosterone inhibition has been shown to have a direct effect to reduce neoinitimal hyperplasia in several models. Eplerenone, a selective aldosterone receptor antagonist, reduces neointimal formation after stent placement [28] and will also suppress constrictive remodeling and collagen accumulation after coronary angioplasty [29]. Thus, the allografts in our study likely did not have sufficient ischemic injury to incite neointimal hyperplasia and therefore this therapeutic effect was not appreciated in our model.

Strain-specific variation in mineralocorticoid expression or response to medication may also play a role. Variations in angiotensin converting enzyme and angiotensin II type I receptor expression in Fisher and Lewis rats has been investigated [24]. Healthy Fisher rats had a 4 fold higher intrarenal angiotensin converting enzyme activity compared to healthy Lewis rats and hypertension-induced renal fibrosis is greatest in rats with the highest mineralocorticoid receptor gene expression $[24,30]$.

Interestingly, rats that received spironolactone had an increased expression of endothelin mRNA. It has been shown that endothelin increases directly and rapidly as a result of direct aldosterone administration [31]. Initially, this seems to be in contrast to previous reported regarding the relationship of aldosterone and spironolactone. However, because spironolactone competitively inhibits aldosterone, there may be an increase in aldosterone blood concentrations via negative feedback mechanisms. While aldosterone was not measured in this study, serum aldosterone concentrations are directly positively related to spironolactone dose in people and cats $[32,33]$. Endothelin is also increased following renal ischemia-reperfusion injury [34], however in the study presented here, endothelin mRNA was most elevated in rats that had only nephrectomy and no ischemic injury.

Functional and histologic changes associated with CAN may be similar to those observed with cyclosporine nephrotoxicity. Cyclosporine nephrotoxicity is a chronic, and at least partially, reversible insult to the allograft. Rats in this experiment were given a relatively low dose of cyclosporine $(1.5 \mathrm{mg} / \mathrm{kg} /$ day $)$ for 10 days after transplantation, thus the changes observed in the model at four months after transplantation are very likely not associated with cyclosporine administration. In another study in rats, cyclosporine given at a dose of $2.5 \mathrm{mg} / \mathrm{kg} /$ day caused minimal to no changes in renal histology or regulation of genes associated with cyclosporine toxicity [35].

Previous studies citing the beneficial effects of spironolactone in preventing renal damage have used doses closer to $20 \mathrm{mg} / \mathrm{kg} / \mathrm{day}$ $[12,18,30,36]$. Interestingly, the dose of spironolactone commonly used in rodent models is dramatically higher than what is generally prescribed to people: $0.3-1.25 \mathrm{mg} / \mathrm{kg}$ for an $80 \mathrm{~kg}$ person or $2 \mathrm{mg} / \mathrm{kg}$ in cats [33] versus $10-20 \mathrm{mg} / \mathrm{kg}$ in rats. Use of spironolactone and other diuretics may be controversial especially in patients with reduced renal function because of the potential for hyperkalemia, alterations in water balance, and occurrence of adverse skin reactions [33].

None the less, in the animals described here and another study [17] using several different doses, there was no improvement in functional parameters of the allograft or amelioration of interstitial fibrosis and glomerulosclerosis, 2 key histologic lesions of CAN. In interpretation of these data, one must take into account that the lack of difference in the transplantation groups with or without lower dose spironolactone treatment may be due to small sample size, sampling at one time point following the ischemic event, and the use of relatively insensitive renal function tests (i.e. serum creatinine concentration). Additional studies evaluating variation in dose and the temporal variations in gene expression are required, as is continued investigation of mechanism of aldosterone-mediated improvement of vasculopathy following ischemic vascular injury. 
Citation: Cogar SM, Schmiedt CW, Brown CA, Vandenplas ML, Chessman C, et al. (2012) Effect of Spironolactone on Chronic Allograft Nephropathy in Rats. J Nephrol Therapeutic S4:002. doi:10.4172/2161-0959.S4-004

Page 5 of 5

\section{Acknowledgement}

Funding provided by the University of Georgia, College of Veterinary Medicine, Veterinary Medical Experiment Station.

\section{Footnotes}

a. Harlan, Indianapolis, IN

b. Colstorsol, Preservation Solutions, Elkhorn, WI

c. RNA-later, Applied Biosystems/Ambion, Houston, TX

d. RNeasy kits, Qiagen, XXXX

e. TaqMan probes and primer kits, Applied Biosystems, Foster City, CA

f. ABI 7900 HT Sequence Detection System, Applied Biosystems/Ambion, Houston, TX

g. GraphPad Prism, V5.02, San Diego, CA

h. SAS version V9.2 Cary, NC

\section{References}

1. De Cock HE, Kyles AE, Griffey SM, Bernsteen L, Gregory CR (2004) Histopathologic findings and classification of feline renal transplants. Vet Pathol 41: $244-256$

2. Kasiske BL, Anjum S, Shah R, Skogen J, Kandaswamy C, et al. (2004) Hypertension after kidney transplantation. Am J Kidney Dis 43: 1071-1081.

3. Sato A, Hayashi K, Naruse M, Saruta T (2003) Effectiveness of aldosterone blockade in patients with diabetic nephropathy. Hypertension 41: 64-68.

4. Fujisawa G, Okada K, Muto S, Fujita N, Itabashi N, et al. (2004) Spironolactone prevents early renal injury in streptozotocin-induced diabetic rats. Kidney Int 66: 1493-1502

5. Blasi ER, Rocha R, Rudolph AE, Blomme EA, Polly ML, et al. (2003) Aldosterone/salt induces renal inflammation and fibrosis in hypertensive rats. Kidney Int 63: 1791-1800.

6. Chander PN, Rocha R, Ranaudo J, Singh G, Zuckerman A, et al. (2003) Aldosterone plays a pivotal role in the pathogenesis of thrombotic microangiopathy in SHRSP. J Am Soc Nephrol 14: 1990-1997.

7. Epstein M, Calhoun DA (2007) The role of aldosterone in resistant hypertension: implications for pathogenesis and therapy. Curr Hypertens Rep 9: 98-105.

8. Rocha R, Chander PN, Zuckerman A, Stier CT Jr (1999) Role of aldosterone in renal vascular injury in stroke-prone hypertensive rats. Hypertension 33: 232 237

9. Hollenberg NK (2004) Aldosterone in the development and progression of renal injury. Kidney Int 66: 1-9.

10. Epstein M (2006) Aldosterone blockade: an emerging strategy for abrogating progressive renal disease. Am J Med 119: 912-919.

11. Greene EL, Kren S, Hostetter TH (1996) Role of aldosterone in the remnan kidney model in the rat. J Clin Invest 98: 1063-1068.

12. Rocha R, Chander PN, Khanna K, Zuckerman A, Stier CT Jr (1998) Mineralocorticoid blockade reduces vascular injury in stroke-prone hypertensive rats. Hypertension 31: 451-458.

13. Rocha R, Stier CT Jr, Kifor I, Ochoa-Maya MR, Rennke HG, et al. (2000) Aldosterone: a mediator of myocardial necrosis and renal arteriopathy. Endocrinology 141: 3871-3878.

14. Zhou X, Ono H, Ono Y, Frohlich ED (2004) Aldosterone antagonism ameliorates proteinuria and nephrosclerosis independent of glomerular dynamics in L-NAME/SHR model. Am J Nephrol 24: 242-249.

15. Brown NJ, Nakamura S, Ma L, Donnert E, Freeman M, et al. (2000) Aldosterone modulates plasminogen activator inhibitor-1 and glomerulosclerosis in vivo. Kidney Int 58: 1219-1227.

16. Kramer AB, van der Meulen EF, Hamming I, van Goor H, Navis G (2007) Effect of combining ACE inhibition with aldosterone blockade on proteinuria and renal damage in experimental nephrosis. Kidney Int 71: 417-424.

17. Waanders F, Rienstra H, Boer MW, Zandvoort A, Rozing J, et al. (2009)
Spironolactone ameliorates transplant vasculopathy in renal chronic transplant dysfunction in rats. Am J Physiol Renal Physiol 296: F1072-1079.

18. Feria I, Pichardo I, Juarez P, Ramírez V, González MA, et al. (2003) Therapeutic benefit of spironolactone in experimental chronic cyclosporine A nephrotoxicity. Kidney Int 63: 43-52.

19. Epstein M, Williams GH, Weinberger M, Lewin A, Krause S, et al. (2006) Selective aldosterone blockade with eplerenone reduces albuminuria in patients with type 2 diabetes. Clin J Am Soc Nephrol 1: 940-951.

20. Rossing K, Schjoedt KJ, Smidt UM, Boomsma F, Parving HH (2005) Beneficial effects of adding spironolactone to recommended antihypertensive treatment in diabetic nephropathy: a randomized, double-masked, cross-over study. Diabetes Care 28: 2106-2112.

21. Schjoedt KJ, Rossing K, Juhl TR, Boomsma F, Rossing P, et al. (2005) Beneficial impact of spironolactone in diabetic nephropathy. Kidney Int 68 2829-2836.

22. Sato A, Hayashi K, Saruta T (2005) Antiproteinuric effects of mineralocorticoid receptor blockade in patients with chronic renal disease. Am J Hypertens 18 44-49.

23. Karatzas T, Santiago S, Xanthos T, de Faria W, Gandia C, et al. (2007) An easy and safe model of kidney transplantation in rats. Microsurgery 27: 668-672.

24. Smit-van Oosten A, Henning $\mathrm{RH}$, van Goor $\mathrm{H}$ (2002) Strain differences in angiotensin-converting enzyme and angiotensin II type I receptor expression. Possible implications for experimental chronic renal transplant failure. J Renin Angiotensin Aldosterone Syst 3: 46-53.

25. Solez K, Colvin RB, Racusen LC, Haas M, Sis B, et al. (2008) Banff 07 classification of renal allograft pathology: updates and future directions. Am J Transplant 8: 753-760.

26. McAnulty JF (2009) Hypothermic organ preservation by static storage methods: Current status and a view to the future. Cryobiology 60: S13-19.

27. Schmiedt CW, Schwab MC, Dubielzig RR, Murphy CJ, McAnulty JF (2007) Trophic factor supplemented UW solution reduces intimal hyperplasia in the rat aortic transplant model. Cryobiology 54: 204-211.

28. Wakabayashi K, Suzuki H, Sato T, Iso Y, Katagiri T, et al. (2006) Eplerenone suppresses neointimal formation after coronary stent implantation in swine. In J Cardiol 107: 260-266.

29. Ward MR, Kanellakis P, Ramsey D, Funder J, Bobik A (2001) Eplerenone suppresses constrictive remodeling and collagen accumulation afte angioplasty in porcine coronary arteries. Circulation 104: 467-472.

30. Cavallari LH, Fashingbauer LA, Camp JR, King ST, Geenen DL (2008) Hypertension-induced renal fibrosis and spironolactone response vary by rat strain and mineralocorticoid receptor gene expression. J Renin Angiotensin Aldosterone Syst 9: 146-153

31. Wong S, Brennan FE, Young MJ, Fuller PJ, Cole TJ (2007) A direct effect of aldosterone on endothelin-1 gene expression in vivo. Endocrinology 148 1511-1517.

32. Cavallari LH, Groo VL, Viana MA, Dai Y, Patel SR, et al. (2010) Association of aldosterone concentration and mineralocorticoid receptor genotype with potassium response to spironolactone in patients with heart failure. Pharmacotherapy 30: 1-9.

33. Macdonald KA, Kittleson MD, Kass PH, White SD (2008) Effect of Spironolactone on Diastolic Function and Left Ventricular Mass in Maine Coon Cats with Familial Hypertrophic Cardiomyopathy. J Vet Intern Med 22: 335-341.

34. Ramirez V, Trujillo J, Valdes R, Uribe N, Cruz C, et al. (2009) Adrenalectomy prevents renal ischemia-reperfusion injury. Am J Physiol Renal Physiol 297 F932-942.

35. Cui Y, Huang Q, Auman JT, Knight B, Jin X, et al. (2011) Genomic-derived markers for early detection of calcineurin inhibitor immunosuppressantmediated nephrotoxicity. Toxicol Sci 124: 23-34

36. Perez-Rojas J, Blanco JA, Cruz C, Trujillo J, Vaidya VS, et al. (2007) Mineralocorticoid receptor blockade confers renoprotection in preexisting chronic cyclosporine nephrotoxicity. Am J Physiol Renal Physiol 292: F131- 